\title{
SEROPREVALENCE AND OCCUPATIONAL RISK SURVEY FOR COXIELLA BURNETII AMONG EXPOSED WORKERS IN SICILY, SOUTHERN ITALY
}

\section{CONCETTINA FENGA ${ }^{1}$, SILVIA GANGEMI ${ }^{1}$, ANNAMARIA DE LUCA ${ }^{1}$, SEBASTIANO CALIMERI ${ }^{2}$, DANIELA LO GIUDICE ${ }^{2}$, MICHELA PUGLIESE ${ }^{3}$, FRANCESCA LICITRA ${ }^{4}$, ANGELA ALIBRANDI' and CHIARA COSTA ${ }^{1}$}

${ }^{1}$ University of Messina, Messina, Italy

Occupational Medicine Section - Department of the Environment, Security, Territory, Food and Health Sciences

${ }^{2}$ University of Messina, Messina, Italy

Department of Biomedical Sciences and Morphological and Functional Images

${ }^{3}$ University of Messina, Messina, Italy

Department of Veterinary Medical Sciences

${ }^{4}$ Veterinary Doctor, Ragusa, Italy

${ }^{5}$ University of Messina, Messina, Italy

Department of Economical, Business and Environmental Sciences and Quantitative Methods

\begin{abstract}
Objectives: The aim of this survey was to assess the seroprevalence of antibodies against Coxiella burnetii (C. burnetii) in subjects at risk of exposure in Sicily, Southern Italy. Material and Methods: Prevalence of IgG antibodies to C. burnetii phase II antigens was evaluated by ELISA in a group of 140 workers at risk of exposure ( 38 veterinarians, 38 slaughterhouse workers, 44 livestock handlers, 20 laboratory and technical personnel) included in a medical surveillance program and in 42 control subjects. Positive samples were classified as suggestive of prior exposure to C. burnetii. Results: Antibodies against $C$. burnetii were detected in 88 out of $140(62.9 \%)$ exposed workers and in 6 out of $42(14.3 \%)$ subjects of the control group. The variables evaluated did not seem to have a significant effect on seropositivity to Coxiella with the exception of symptoms in the last 6 months preceding the survey. Conclusions: Our study demonstrated a high seroprevalence of $C$. burnetii in the group of exposed workers in comparison to non-exposed subjects of the control group. Clinical illness appears to be rare; nevertheless, physicians should consider Q fever in patients with compatible symptoms and occupational exposure to animals and their products. As aerosols represent the main route of infection in animals and humans, these workers are strongly advised to wear respiratory masks. In addition, occupational physicians should consider routine serologic evaluation and vaccination of occupationally exposed workers.
\end{abstract}

Key words:

Seroprevalence, Coxiella burnetii, Occupational hazard, Anthropozoonosis, Health surveillance, Prevention

Received: September 2, 2014. Accepted: November 26, 2014.

Corresponding author: S. Gangemi, University of Messina, Occupational Medicine Section, Department of the Environment, Security, Territory, Food and Health Sciences, Policlinico Universitario “G. Martino,” Via Consolare Valeria 1, Messina 98125, Italy (e-mail: silviagangemi@hotmail.com). 


\section{INTRODUCTION}

Q fever is caused by the obligate intracellular bacterium Coxiella burnetii. This zoonotic disease is endemic throughout the world, occurring in diverse geographic regions and climate zones.

Infected domestic animals, particularly sheep, goats, cattle and cats (but also dogs, horses, rabbits and other animals) represent the main source of infection for humans, but free-living mammals and birds are also important reservoirs [1-4].

In humans, infection is usually acquired from aerosols generated from infected placenta, body fluids or contaminated dust, after desiccation of the primary source. People can also acquire infection by ingestion of unpasteurized dairy products [5] and direct contact with material contaminated with animal excreta [6]. The clinical signs of Q fever in humans are often described as "flu-like," but the illness may vary from self-limiting non-specific fever to atypical pneumonia, endocarditis, hepatitis and neurological manifestation [7].

Q fever is also recognized as an occupational risk for people who work with animals or animal products, including veterinarians, sheep and dairy workers, meat processing plant workers, laboratory workers, hide handlers, wool spinners, taxidermists and butchers [8]. Few occupational health studies have been conducted to examine occupational exposure and rates of infection among exposed workers [9].

In Italy, a seroprevalence of Q fever in sheep, goats, cows and buffaloes has been reported, and the presence of DNA of $C$. burnetii in dogs was $31.5 \%$ in Sicilian area and $7 \%$ in Southern Italy $[10,11]$. Despite these findings, few data are reported in Italy on the seroprevalence of $C$. burnetii in humans $[12,13]$; but there are no data in occupationally exposed subjects in Sicily.

The aim of this survey was to assess the seroprevalence of antibodies against $C$. burnetii in a group of exposed workers and to identify possible risk factors.

\section{MATERIAL AND METHODS}

A group of 140 workers at risk for exposure to C. burnetii (38 veterinarians, 38 slaughterhouse workers, 44 livestock handlers, 20 laboratory and technical personnel) were recruited as study subjects.

All participants were Caucasians, age: $25-75$ years (mean \pm standard deviation: $48.45 \pm 10.81$ ), length of employment: $28.45 \pm 9.75$ years. All workers were included in a medical surveillance program for the prevention of occupational diseases and gave their informed consent before inclusion into the study.

In order to obtain sociodemographic, occupational and clinical data, all participants included in the study were interviewed by a well-trained occupational physician to fill out a questionnaire providing the following information: sex, age, residence (rural or urban); profession and occasional temporary work during which the individual came into contact with hay, soil, manure, animal skins and furs, wool, milk, meat and similar, or work in a dusty environment; use of respiratory and skin protection devices; sporting activities associated with animals; stay abroad with potential contact with animals and their products; consumption of raw meat, non-pasteurized milk and dairy products; pet ownership; contact with farm animals or pregnant dog or cat; tick bite.

Clinical history interview included questions on fever of unknown origin, flu-like symptoms during the last 6 months, rheumatic disease, diseases involving heart, liver, respiratory tract (atypical pneumonia), chronic fatigue syndrome and in females also spontaneous abortion.

After the completion of the survey, a single blood sample was collected in a $10 \mathrm{ml}$ serum separator from each participant and stored at $-20^{\circ} \mathrm{C}$ until analysis.

The control group consisted of 42 samples collected from healthy blood donors, comparable for age and sex to the study subjects, employed in public offices and in whom questionnaire indicated no known risk factor for exposure to $C$. burnetii. 
Sera from workers and controls were tested by a $\mathrm{Q}$ fever phase II IgG ELISA kit (PanBio, Brisbane, Australia) according to the manufacturer's instructions. Microwell plates were finally read in a microtiter plate reader at a wavelength of $450 \mathrm{~nm}$. Positive control, negative control and triplicate wells with calibrator control sera were used on each plate. Data were analyzed according to the protocol provided by manufacturer. Briefly, sample absorbance was divided by the average absorbance of calibrator control wells, then multiplied by 10 to obtain "PanBio units." Samples with calculated PanBio units $<9$ were considered negative, samples with PanBio units 9-11 were equivocal and with $>11$ PanBio units were considered positive results. Positive samples were classified as suggestive of prior exposure to C. burnetii.

Logistic Regression Models [14] were evaluated to verify the possible dependence of the results (positive or negative) on some potential explicative variables, such as age, sex, work place, smoking status, intake of crude food etc. Only for subjects with symptoms we investigated the association between flu-like and not flu-like symptoms and the results, using the Log-likelihood Ratio test. Statistical analyses were performed using SPSS 11.0 for Windows package. P value below 0.05 was considered to be statistically significant.

\section{RESULTS}

Data provided by questionnaires regarding sociodemographic characteristics, occupational and clinical history are shown in Table 1. A total of 88/140 (62.9\%) subjects met the criteria for seropositivity to $C$. burnetii. Six out of $42(14.3 \%)$ subjects of the control group were positive for IgG to C. burnetii. Table 1 also reports the seroprevalence of phase II IgG for $C$. burnetii in the different subpopulations individuated by questionnaire submission.

Application of logistic regression models on the variables evaluated did not seem to have a significant effect on seropositivity to Coxiella, with the exception of symptoms in the last 6 months preceding the survey (Table 2).
Table 1. Sociodemographic and clinical characteristics and seropositivity for $C$. burnetii in study group

\begin{tabular}{|c|c|c|}
\hline \multirow{2}{*}{ Variable } & \multicolumn{2}{|c|}{$\begin{array}{l}\text { Respondents } \\
\quad[\mathrm{n}(\%)]\end{array}$} \\
\hline & $\begin{array}{c}\text { total } \\
(\mathrm{N}=140) \\
\end{array}$ & $\begin{array}{l}\text { with } \operatorname{IgG} \text { for } \\
\text { C. burnetii }\end{array}$ \\
\hline \multicolumn{3}{|c|}{ Presence of $\operatorname{IgG}$ for $C$. burnetii } \\
\hline negative & $52(37.1)$ & \\
\hline positive & $88(62.9)$ & \\
\hline \multicolumn{3}{|l|}{ Sex } \\
\hline male & $136(97.1)$ & $86(63.2)$ \\
\hline female & $4(2.9)$ & $2(50.0)$ \\
\hline \multicolumn{3}{|l|}{ Residence } \\
\hline urban & $112(80)$ & $70(62.5)$ \\
\hline rural & $28(20)$ & $18(64.3)$ \\
\hline \multicolumn{3}{|l|}{ Job type } \\
\hline veterinary & $38(27.1)$ & $28(73.7)$ \\
\hline slaughterer & $38(27.1)$ & $28(73.7)$ \\
\hline animal farmer & $44(31.4)$ & $24(54.5)$ \\
\hline other & $20(14.3)$ & $8(40.0)$ \\
\hline occasional exposure & $0(0)$ & - \\
\hline \multicolumn{3}{|l|}{ Workplace } \\
\hline slaughterhouse & $46(32.9)$ & $36(78.3)$ \\
\hline laboratory & $12(8.6)$ & $6(50.0)$ \\
\hline animal farm & $82(58.6)$ & $46(56.1)$ \\
\hline \multicolumn{3}{|l|}{ Smoking } \\
\hline no & $96(68.6)$ & $60(62.5)$ \\
\hline yes & $44(31.4)$ & $28(63.6)$ \\
\hline \multicolumn{3}{|l|}{ Drug intake } \\
\hline no & $108(77.1)$ & $60(55.5)$ \\
\hline yes & $32(22.9)$ & $28(87.5)$ \\
\hline \multicolumn{3}{|l|}{ Raw food consumption } \\
\hline no & $108(77.1)$ & $64(59.3)$ \\
\hline yes & $32(22.0)$ & $24(75.0)$ \\
\hline \multicolumn{3}{|c|}{$\begin{array}{l}\text { Sporting activity involving } \\
\text { animals }\end{array}$} \\
\hline no & $134(95.7)$ & $82(61.2)$ \\
\hline yes & $6(4.3)$ & $6(100)$ \\
\hline \multicolumn{3}{|l|}{ Exposure abroad } \\
\hline no & $140(100)$ & $88(62.9)$ \\
\hline yes & $0(0)$ & - \\
\hline
\end{tabular}


Table 1. Sociodemographic and clinical characteristics and seropositivity for $C$. burnetii in study group - cont.

\begin{tabular}{lcc}
\hline \multirow{2}{*}{ Variable } & \multicolumn{2}{c}{ Respondents } \\
\cline { 2 - 3 } & total $(\%)]$ & with IgG for \\
& $(\mathrm{N}=140)$ & C. burnetii \\
\hline Pets & $103(73.6)$ & $61(59.2)$ \\
no & $37(26.4)$ & $27(73.0)$ \\
yes & & \\
Non-occupational contact & & \\
with animals & $134(95.7)$ & $85(63.4)$ \\
no & $6(4.3)$ & $3(50.0)$ \\
yes & & \\
Use of respiratory protection & & \\
devices & $140(100)$ & $88(62.9)$ \\
no & $0(0)$ & - \\
yes & & \\
Use of gloves & $29(20.7)$ & $25(86.2)$ \\
no & $111(79.3)$ & $63(56.8)$ \\
$\quad$ yes & & \\
Symptoms in the last 6 months & & $64(66.7)$ \\
no & $96(68.6)$ & $24(54.5)$ \\
\hline yes & $44(31.4)$ &
\end{tabular}

Table 2. Association between prior exposure to $C$. burnetii and presence of symptoms in the last 6 months in study group

\begin{tabular}{|c|c|c|}
\hline \multirow[t]{2}{*}{ Symptom } & \multicolumn{2}{|c|}{$\begin{array}{c}\text { Respondents with } \operatorname{IgG} \\
\text { for } C \text {. burnetii } \\
{[\mathrm{n}]}\end{array}$} \\
\hline & negative & positive \\
\hline Not flu-like & 0 & 6 \\
\hline Flu-like & 20 & 18 \\
\hline Likelihood ratio & \multicolumn{2}{|c|}{$p=0.045$} \\
\hline
\end{tabular}

\section{DISCUSSION AND CONCLUSIONS}

In this cross-sectional study, an overall $C$. burnetii seroprevalence of $62.9 \%$ among occupationally exposed workers was found.

Few data are reported in Italy on the seroprevalence of C. burnetii in humans [15-18] and little is known about occupational risk for the above mentioned zoonosis. In the current study, the 1st that demonstrated a seropositivity for $C$. burnetii in occupationally exposed workers in Sicily, there was a seroprevalence higher than that reported in a previous study conducted in Northern Italy (50\%) in agricultural workers [12].

Our results are also similar to those reported in France (71\%), in Netherlands (83.8\%) [19] and in Slovakia (63\%) [20]. International prevalence rates vary greatly. For example, published prevalence rates for cattle workers in Sweden, Austria, Bavaria and Spain vary from $10 \%$ to $30 \%$ [21-25]. Such variation may reflect either geographical differences and/or variable sensitivity of the available testing techniques (e.g., complement fixation test - CFT, ELISA, immunofluorescence assay, skin prick testing) [8].

The results of the present study also showed a positive correlation between subjects positive for $\operatorname{IgG}$ to $C$. burnetii and those reporting either flu-like or not flu-like symptoms in the last 6 months.

In general, clinical illness appears to be rare; nevertheless, physicians should consider Q fever in patients with compatible symptoms and occupational exposure to animals and their products [24]. The infection by $C$. burnetii in the population studied was not significantly affected by drinking unpasteurized milk, age and sex. The role of unpasteurized milk in C. burnetii infection is controversial. In agreement with the findings of the current study, other authors reported that the age- or sex-related differences were not detected in human $\mathrm{Q}$ fever. However, there are reports of associations of age and sex [26].

In our study, 70 subjects lived in rural, and 18 in urban area. Residence in rural dwellings was not a statistically significant risk factor for seropositivity; nevertheless, various authors demonstrated that subjects living in rural and sub-urban area were significantly more often seropositive than subjects living in an urban area [20,27].

The results also showed a seroprevalence rate of $78.3 \%$ among veterinarians and slaughterhouse workers and 
a rate of $54.5 \%$ in animal farmers. The frequency of antibody is constant, irrespective of type of occupation. This suggests that the organism is widely dispersed in such environments and that all employees in such areas are at risk of exposure. Furthermore the questionnaire indicated that, with the exception of 8 subjects (laboratory and technical personnel), all employees with a high seroprevalence for $C$. burnetii reported a frequent contact with hay, manure, soil and straw and animal products, which is natural regarding the respective profession. Hay on the floor of animal housings is contaminated by C. burnetii in faeces, urine and birth products. Removing the bedding would generate aerosols containing C. burnetii [20]. These findings are consistent with what is known of the biology of Q fever. C. burnetii differs from others rickettsia crucially in its resistance to physical conditions - such as extremes of temperature and desiccation. As a consequence, infection in an animal reservoir may result in wide dissemination of the organism in the environment [28,29].

Among exposed workers who reported using various personal protective equipment, all subjects reported never wearing a mask. This could explain the high seropositivity to $C$. burnetii observed in our sample. In fact, the contamination by aerosols represents the main route of infection in animals and humans. As a result, a suitable prevention must be guaranteed and people who work in contact with animals should wear appropriate personal protective equipment, including a lab coat or equivalent and a mask, when treating animals possibly infected with $C$. burnetii and especially when assisting birth, or during the handling of birth products of animals known to be carriers of $C$. burnetii.

Public health policy (e.g. pasteurization of milk and milk products, and the provision of adequate quarantine facilities for imported animals) and farm hygienic measures (such as manure sterilization/composting and management, disinfection of the paths and ways to the pastures, air filter systems in housing and movement controls) are effective in reducing infection risk [19].

Measures that can be applied to reduce environmental transmission of $C$. burnetii from infected animals to humans also include vaccination. There is evidence that vaccine for goat and sheep can reduce the number of infections and abortions, as well as decrease the environmental transmission of the pathogen [30,31]. A vaccine against $C$. burnetii has been developed for use in humans and it is available in Italy and throughout the whole of the European Union. Preexposure vaccination of those in high-risk occupations is routinely carried out in some countries, and has been shown to be both safe and $100 \%$ effective for at least 5 years [8]. In conclusion, exposed workers should consider undergoing routine serologic follow-up as well as obey basic safety rules in order to better define the risk and if necessary take appropriate measures to prevent zoonotic diseases.

\section{REFERENCES}

1. DeLay PD, Lennette EH, Deome KB. Q fever in California: Recovery of Coxiella Burnetii from naturally-infected airborne dust. J Immunol. 1950;65:211-20.

2. Welsh HH, Lennette EH, Abinanti FR, Winn JF, Kaplan W. Q fever studies: The recovery of Coxiella burnetii from the soil and surface water of premises arboring infected sheep. Am J Hyg. 1959;70(1):14-20.

3. Woldehiwet Z. Q fever (coxiellosis): Epidemiology and pathogenesis. Res Vet Sci. 2004;77(3):93-100, http://dx.doi. org/10.1016/j.rvsc.2003.09.001.

4. McQuiston JH, Holman RC, McCall CL, Childs JE, Swerdlow DL, Thompson HA. National surveillance and the epidemiology of human Q fever in the United States, 1978-2004. Am J Trop Med Hyg. 2006;75(1):36-40.

5. Oren I, Kraoz Z, Hadani Y, Kassis I, Zaltzman-Bershadsky N, Finkelstein R. An outbreak of Q fever in an urban area in Israel. Eur J Clin Microbiol Infect Dis. 2005;24(5):338-41.

6. Babudieri B. Q fever: A zoonosis. Adv Vet Sci. 1959;5:81-154, http://dx.doi.org/10.1007/s10096-005-1324-8. 
7. Marrie TJ. Q fever. Can Vet J. 1990;31(8):555-63.

8. Reid A, Malone J. Q fever in Ireland. A seroprevalence study of exposure to Coxiella burnettii among Department of Agriculture workers. Occup Med (Lond). 2004;54(8):544-7, http://dx.doi.org/10.1093/occmed/kqh086.

9. Whitney EA, Massung R, Candee A, Ailes E, Myers L, Patterson N, et al. Seroepidemiologic and occupational risk survey for Coxiella burnetii antibodies among US veterinarians. Clin Infect Dis. 2009;48(5):550-7, http://dx.doi. org/10.1086/596705.

10. Torina A, Caracappa S. Dog tick-borne diseases in Sicily. Parassitologia. 2006;48(1-2):145-7.

11. Capuano F, Parisi A, Cafiero MA, Picaro L, Fenizia D. [Coxiella burnetii: What is the reality?] Parassitologia. 2004;46(1-2):131-4. Italian.

12. Tabibi R, Baccalini R, Barassi A, Bonizzi L, Brambilla G, Consonni $\mathrm{D}$, et al. Occupational exposure to zoonotic agents among agricultural workers in Lombardy Region, Northern Italy. Ann Agric Environ Med. 2013;20(4):676-81.

13. Fenga C, Pugliese M. Endemic zoonosis in Mediterranean area. G Ital Med Lav Ergon. 2013;35(4):347-9.

14. Kleinbaum DG, Klein M. Logistic regression: A self-learning text. 2nd ed. New York: Springer-Verlag; 2002.

15. Tringali $\mathrm{G}$, Mansueto $S$. Epidemiology of $\mathrm{Q}$ fever in Italy and in other Mediterranean countries. Zentralbl Bakteriol Mikrobiol Hyg A. 1987;267(1):20-5, http://dx.doi.org/10.1016/ s0176-6724(87)80181-5.

16. Manfredi Selvaggi T, Rezza G, Scagnelli M, Rigoli R, Rassu M, de Lalla F, et al. Investigation of a Q-fever outbreak in Northern Italy. Eur J Epidemiol. 1996;12(4):403-8, http:// dx.doi.org/10.1007/BF00145305.

17. Cinco M, Luzzati R, Mascioli M, Floris R, Brouqui P. Serological evidence of Rickettsia infections in forestry rangers in north-eastern Italy. Clin Microbiol Infect. 2006;12(5): 493-5, http://dx.doi.org/10.1111/j.1469-0691.2006.01385.x.

18. Monno R, Fumarola L, Trerotoli P, Cavone D, Massaro T, Spinelli L, et al. Seroprevalence of Q-fever, brucellosis and leptospirosis in farmers and agricultural workers in Bari, southern Italy. Clin Microbiol Infect. 2009;15(2):142-3, http://dx.doi.org/10.1111/j.1469-0691.2008.02151.x.

19. Georgiev M, Afonso A, Neubauer H, Needham H, Thiery R, Rodolakis A, et al. Q fever in humans and farm animals in four European countries, 1982-2010. Euro Surveill. 2013;18(8).

20. Dorko E, Kalinovà Z, Weissovà T, Pilipeinec E. Seroprevalence of antibiodes to Coxiella burnetii among employees of the veterinary University in Kosice, eastern Slovakia. Ann Agric Environ Med. 2008;15(1):119-24.

21. Cisak E, Chmielewska-Badora J, Mackiewicz B, Dutkiewicz J. Prevalence of antibodies to Coxiella burnetii among farming population in eastern Poland. Ann Agric Environ Med. 2003;10(2):265-7.

22. Macellaro A, Akesson A, Norlander L. A survey of Q-fever in Sweden. Eur J Epidemiol. 1993;9(2):213-6, http://dx.doi. org/10.1007/BF00158795.

23. Nowotny N, Deutz A, Fuchs K, Schuller W, Hinterdorfer F, Auer $\mathrm{H}$, et al. Prevalence of swine influenza and other viral, bacterial, and parasitic zoonoses in veterinarians. J Infect Dis. 1997;176(5):1414-5, http://dx.doi.org/10.1086/517337.

24. Bernard H, Brockmann SO, Kleinkauf N, Klinc C, WagnerWiening C, Stark K, et al. High seroprevalence of Coxiella burnetii antibodies in veterinarians associated with cattle obstetrics, Bavaria, 2009. Vector Borne Zoonotic Dis. 2012;12(7):552-7, http://dx.doi.org/10.1089/vbz.2011.0879.

25. Valencia MC, Rodriguez CO, Puñet OG, de Blas Giral I. Q fever seroprevalence and associated risk factors among students from the Veterinary School of Zaragoza, Spain. Eur J Epidemiol. 2000;16(5):469-76, http://dx.doi. org/10.1023/A:1007605414042.

26. Adesiyun A, Dookeran S, Stewart-Johnson A, Rahaman S, Bissessar S. Frequency of seropositivity for Coxiella burnetii immunoglobulins in livestock and abattoir workers in Trinidad. New Microbiol. 2011;34(2):219-24.

27. Van den Brom R, Schimmer B, Schneeberger PM, Swart WA, van der Hoek W, Vellema P. Seroepidemiological survey for Coxiella burnetii antibodies and associated risk factors in 
Dutch livestock veterinarians. PLoS One. 2013;8(1):e54021, http://dx.doi.org/10.1371/journal.pone.0054021.

28. Thomas DR, Treweek L, Salmon RL, Kench SM, Coleman TJ, Meadows D, et al. The risk of acquiring Q fever on farms: A seroepidemiological study. Occup Environ Med. 1995;52(10):644-7, http://dx.doi.org/10.1136/oem. 52.10 .644 .

29. Fenga C, Cacciola A, Di Nola C, Calimeri S, Lo Giudice D, Pugliese M, et al. Serologic investigation of the prevalence of Chlamydophila psittaci in occupationally-exposed subjects in eastern Sicily. Ann Agric Environ Med. 2007; 14(1):93-6.

30. Hogerwerf L, van den Brom R, Roest HI, Bouma A, Vellema P, Pieterse M, et al. Reduction of Coxiella burnetii prevalence by vaccination of goats and sheep, The Netherlands. Emerg Infect Dis. 2011;17(3):379-86, http://dx.doi. org/10.3201/eid1703.101157.

31. Bielawska-Drózd A, Cieślik P, Mirski T, Bartoszcze M, Knap JP, Gaweł J, et al. Q fever - Selected issues. Ann Agric Environ Med. 2013;20(2):222-32.

This work is available in Open Access model and licensed under a Creative Commons Attribution-NonCommercial 3.0 Poland License - http://creativecommons.org/ licenses/by-nc/3.0/pl/deed.en. 